\title{
On highly efficient derivative-free family of numerical methods for solving polynomial equation simultaneously
}

\author{
Mudassir Shams ${ }^{1 *}$, Naila Rafiq ${ }^{2}$, Nasreen Kausar ${ }^{3}$, Praveen Agarwal ${ }^{4,5}$, Choonkil Park $^{6 *}$ and \\ Nazir Ahmad Mir ${ }^{2}$
}

"Correspondence:

shams6262@gmail.com;

baak@hanyang.ac.kr

${ }^{1}$ Department of Mathematics and

Statistics, Riphah International

University I-14, Islamabad 44000,

Pakistan

${ }^{6}$ Department of Mathematics,

Research Institute of Natural

Science, Hanyang University, Seoul,

South Korea

Full list of author information is

available at the end of the article

\begin{abstract}
A highly efficient new three-step derivative-free family of numerical iterative schemes for estimating all roots of polynomial equations is presented. Convergence analysis proved that the proposed simultaneous iterative method possesses 12 th-order convergence locally. Numerical examples and computational cost are given to demonstrate the capability of the method presented.
\end{abstract}

Keywords: Numerical scheme; Polynomials; Computational efficiency; CPU-time; Convergence order

\section{Introduction}

A lot of engineering and physical problems can be formulated as a nonlinear polynomial equation

$$
f(r)=r^{n}+a_{n-1} r^{n-1}+\cdots+a_{0}=\prod_{j=1}^{n}\left(r-\zeta_{j}\right)=\left(r-\zeta_{i}\right) \prod_{\substack{j=1 \\ j \neq i}}^{n}\left(r-\zeta_{j}\right),
$$

where $\zeta_{1} \cdots \zeta_{n}$ denote all the simple or complex roots of (1). Classical Newton's method has local quadratic convergence given as

$$
s^{(t)}=r^{(t)}-\frac{f\left(r^{(t)}\right)}{f^{\prime}\left(r^{(t)}\right)} \quad(t=0,1, \ldots, n) .
$$

But method (2) has a major drawback, i.e., it requires evaluation of derivative at each step, which requires high computational cost. To overcome this, using forward difference approximation of $f^{\prime}\left(r^{(t)}\right)$

$$
f^{\prime}\left(r^{(t)}\right) \cong \frac{f\left(r^{(t)}+f\left(r^{(t)}\right)\right)-f\left(r^{(t)}\right)}{f\left(r^{(t)}\right)},
$$

(c) The Author(s) 2021. This article is licensed under a Creative Commons Attribution 4.0 International License, which permits use, sharing, adaptation, distribution and reproduction in any medium or format, as long as you give appropriate credit to the original author(s) and the source, provide a link to the Creative Commons licence, and indicate if changes were made. The images or other third party material in this article are included in the article's Creative Commons licence, unless indicated otherwise in a credit line to the material. If material is not included in the article's Creative Commons licence and your intended use is not permitted by statutory regulation or exceeds the permitted use, you will need to obtain permission directly from the copyright holder. To view a copy of this licence, visit http://creativecommons.org/licenses/by/4.0/. 
in (2), we get Steffensen's iterative method [1] of convergence order 2:

$$
s^{(t)}=r^{(t)}-\frac{\left(f\left(r^{(t)}\right)\right)^{2}}{f\left(r^{(t)}+f\left(r^{(t)}\right)\right)-f\left(r^{(t)}\right)} .
$$

Later, Farooq et al. [2] presented the following derivative-free method having local quadratic convergence:

$$
s^{(t)}=r^{(t)}-\frac{\alpha\left(f\left(r^{(t)}\right)\right)^{2}}{f\left(r^{(t)}+\alpha f\left(r^{(t)}\right)\right)-f\left(r^{(t)}\right)},
$$

where $\alpha \in \mathbb{R}$. In the last few years, a lot of work has been done on those numerical iterative methods which approximate single root at one time of (1) (see, e.g., [3-7]). Besides these single root estimating methods in literature, we found another class of derivative-free iterative schemes which approximate all roots of (1) simultaneously. Iterative methods for approximating all roots of (1) have been very popular in recent years due to their global convergence and parallel implementation on computer (see, e.g., Weierstrass [8], Kanno [9], Proinov [10], Petković [11], Mir [12], Nourein [13], Aberth [14] and the references cited therein [15-23]).

Among derivative-free simultaneous methods, Weierstrass-Dochive [24] method is the most attractive method given by

$$
s_{i}^{(t)}=r_{i}^{(t)}-w\left(r_{i}^{(t)}\right),
$$

where

$$
w\left(r_{i}^{(t)}\right)=\frac{f\left(r_{i}^{(t)}\right)}{\prod_{\substack{j \neq 1 \\ j \neq i}}^{n}\left(r_{i}^{(t)}-r_{j}^{(t)}\right)} \quad(i, j=1,2,3, \ldots, n)
$$

is Weierstrass correction. Method (6) has local quadratic convergence.

Nedzibove et al. [25] presented the following simultaneous method having a local quadratic convergence:

$$
z_{i}^{(t)}=y_{i}^{(t)}-\frac{f\left(r_{i}^{(t)}\right) w\left(r_{i}^{(t)}\right)}{f\left(r_{i}^{(t)}\right)-f\left(y_{i}^{(t)}\right)},
$$

where $y_{i}^{(t)}=r_{i}^{(t)}-w\left(r_{i}^{(t)}\right)$.

Petkovic et al. [11] escalated the convergence order of Ehrlich iterative numerical schemes from three to ten (abbreviated as NIM10):

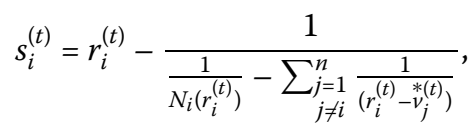

where $v_{j}^{*(t)}=u_{j}^{(t)}-\frac{\left(v_{j}^{(t)}-u_{j}^{(t)}\right) f\left(u_{j}^{(t)}\right)\left(\frac{f\left(r_{j}^{(t)}\right)}{f^{\prime}\left(r_{j}^{(t)}\right)}\right)}{\left(f\left(r_{j}^{(t)}\right)-f\left(u_{j}^{(t)}\right)\right)^{2}}\left[f\left(y_{j}^{(t)}\right)-\frac{\left(f\left(r_{j}^{(t)}\right)\right)^{2}}{f\left(v_{j}^{(t)}\right)-f\left(u_{j}^{(t)}\right)}\right], u_{j}^{(t)}=y_{j}^{(t)}-\frac{f\left(r_{j}^{(t)}\right) f\left(y_{j}^{(t)}\right)\left(\frac{f\left(r_{j}^{(t)}\right)}{f^{\prime}\left(r_{j}^{(t)}\right)}\right)}{\left(f\left(r_{j}^{(t)}\right)-f\left(y_{j}^{(t)}\right)\right)^{2}}, y_{j}^{(t)}=$ $r_{j}^{(t)}-\frac{f\left(r_{j}^{(t)}\right)}{f^{\prime}\left(r_{j}^{(t)}\right)}$. 
The main aim of this paper is to construct a high order efficient derivative-free family of methods among all existing simultaneous methods in the literature.

\section{Construction of simultaneous method}

Consider well-known three-step Newton methods [26] of convergence order eight as follows:

$$
v^{(t)}=u^{(t)}-\frac{f\left(u^{(t)}\right)}{f^{\prime}\left(u^{(t)}\right)}
$$

where $u^{(t)}=s^{(t)}-\frac{f\left(s^{(t)}\right)}{f^{\prime}\left(s^{(t)}\right)}$ and $s^{(t)}=r^{(t)}-\frac{f\left(r^{(t)}\right)}{f^{\prime}\left(r^{(t)}\right)}$. Taking Weierstrass correction [24]

$$
\frac{f\left(r_{i}^{(t)}\right)}{f^{\prime}\left(r_{i}^{(t)}\right)}=w\left(r_{i}^{(t)}\right)=\frac{f\left(r_{i}^{(t)}\right)}{\prod_{\substack{j=1 \\ j \neq i}}^{n}\left(r_{i}^{(t)}-r_{j}^{(t)}\right)}
$$

and replacing $r_{j}^{(t)}=\stackrel{*}{s}{ }_{j}^{(t)}$ in $(10)$, we have

$$
\frac{f\left(r_{i}^{(t)}\right)}{f^{\prime}\left(r_{i}^{(t)}\right)}=\frac{f\left(r_{i}^{(t)}\right)}{\prod_{\substack{j=1 \\ j \neq i}}^{n}\left(r_{i}^{(t)}-s_{j}^{*(t)}\right)}
$$

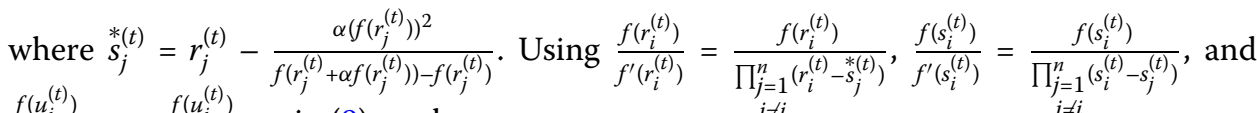
$\frac{f\left(u_{i}^{(t)}\right)}{f^{\prime}\left(u_{i}^{(t)}\right)}=\frac{f\left(u_{i}^{(t)}\right)}{\prod_{\substack{j=1 \\ j \neq i}}^{n}\left(u_{i}^{(t)}-u_{j}^{(t)}\right)}$ in $(9)$, we have

$$
v_{i}^{(t)}=u_{i}^{(t)}-\frac{f\left(u_{i}^{(t)}\right)}{\prod_{\substack{j=1 \\ j \neq i}}^{n}\left(u_{i}^{(t)}-u_{j}^{(t)}\right)}
$$

where $u_{i}^{(t)}=s_{i}^{(t)}-\frac{f\left(s_{i}^{(t)}\right)}{\prod_{\substack{j=1 \\ j \neq i}}^{n}\left(s_{i}^{(t)}-s_{j}^{(t)}\right)}$ and $s_{i}^{(t)}=r_{i}^{(t)}-\frac{f\left(r_{i}^{(t)}\right)}{\prod_{\substack{j=1 \\ j \neq i}}^{n}\left(r_{i}^{(t)}-s_{j}^{*(t)}\right)}$.

Thus, we have constructed a new simultaneous iterative method (12), which is abbreviated as NIM12.

\subsection{Convergence aspect}

In this section, we prove that method NIM12 has local convergence order 12.

Theorem 1 Let $\zeta_{1}, \ldots, \zeta_{n}$ be the $n$ simple roots of $(1)$. If $r_{1}^{(0)}, \ldots, r_{n}^{(0)}$ are the initial estimates of the roots respectively and sufficiently close to actual roots, then NIM12 has a convergence order 12.

Proof Let $\epsilon_{i}=r_{i}^{(t)}-\zeta_{i}, \epsilon_{i}^{\prime}=s_{i}^{(t)}-\zeta_{i}, \epsilon_{i}^{\prime \prime}=u_{i}^{(t)}-\zeta_{i}$, and $\epsilon_{i}^{\prime \prime \prime}=v_{i}^{(t)}-\zeta_{i}$ be the errors in $r_{i}, s_{i}, u_{i}$, and $v_{i}$, respectively. From (12), the first step of NIM12, we have

$$
s_{i}^{(t)}-\zeta_{i}=r_{i}^{(t)}-\zeta_{i}-w_{i}\left(r_{i}^{(t)}\right)
$$




$$
\begin{aligned}
& \epsilon_{i}^{\prime}=\epsilon_{i}-\epsilon_{i} \frac{w_{i}\left(r_{i}^{(t)}\right)}{\epsilon_{i}}, \\
& \epsilon_{i}^{\prime}=\epsilon_{i}\left(1-E_{i}\right),
\end{aligned}
$$

where

$$
\begin{aligned}
& E_{i}=\frac{w_{i}\left(r_{i}^{(t)}\right)}{\epsilon_{i}}=\prod_{\substack{j \neq i \\
j=1}}^{n} \frac{\left(r_{i}^{(t)}-\zeta_{j}\right)}{\left(r_{i}^{(t)}-\stackrel{*}{s}_{j}^{(t)}\right)}, \\
& \frac{r_{i}^{(t)}-\zeta_{j}}{r_{i}^{(t)}-{ }^{*} s_{j}^{(t)}}=1+\frac{\stackrel{*}{s}(t)_{j}^{(t)}-\zeta_{j}}{r_{i}^{(t)}-{ }^{*}(t)}=1+O\left(\epsilon^{2}\right),
\end{aligned}
$$

and $s_{j}^{*}(t)-\zeta_{j}=O\left(\epsilon^{2}\right)$ see [2]. For a simple root $\zeta$ and small enough $\epsilon,\left|r_{i}^{(t)}-{ }_{s}^{*}(t)\right|$ is bounded away from zero, and so

$$
\begin{aligned}
& \prod_{\substack{j \neq i \\
j=1}}^{n} \frac{\left(r_{i}^{(t)}-\zeta_{j}\right)}{\left.\left(r_{i}^{(t)}-\stackrel{*}{s}_{j}^{(t)}\right)\right)}=\left(1+O\left(\epsilon^{2}\right)\right)^{n-1}=1+(n-1) O\left(\epsilon^{2}\right)=1+O\left(\epsilon^{2}\right), \\
& E_{i}=1+O\left(\epsilon^{2}\right) \\
& E_{i}-1=O\left(\epsilon^{2}\right) .
\end{aligned}
$$

Thus, (13) gives

$$
\epsilon_{i}^{\prime}=O(\epsilon)^{3}
$$

From the second step of NIM12, we have

$$
\begin{aligned}
& u_{i}^{(t)}-\zeta_{i}=s_{i}^{(t)}-\zeta_{i}-w_{i}\left(s_{i}^{(t)}\right), \\
& \epsilon_{i}^{\prime \prime}=\epsilon_{i}^{\prime}-\epsilon_{i}^{\prime} \frac{w_{i}\left(s_{i}^{(t)}\right)}{\epsilon_{i}^{\prime}}, \\
& \epsilon_{i}^{\prime \prime}=\epsilon_{i}^{\prime}\left(1-U_{i}\right),
\end{aligned}
$$

where

$$
\begin{aligned}
& U_{i}=\frac{w_{i}\left(s_{i}^{(t)}\right)}{\epsilon_{i}^{\prime}}=\prod_{\substack{j \neq i \\
j=1}}^{n} \frac{\left(s_{i}^{(t)}-\zeta_{j}\right)}{\left.(t)-s_{j}^{(t)}\right)}, \\
& \frac{s_{i}^{(t)}-\zeta_{j}}{s_{i}^{(t)}-s_{j}^{(t)}}=1+\frac{s_{i}^{(t)}-\zeta_{j}}{s_{i}^{(t)}-s_{j}^{(t)}}=1+O\left(\epsilon_{i}^{\prime}\right) .
\end{aligned}
$$

For a simple root $\zeta$ and small enough $\epsilon,\left|s_{i}^{(t)}-\stackrel{(t)}{s}{ }_{j}\right|$ is bounded away from zero, so

$$
\prod_{\substack{j \neq i \\ j=1}}^{n} \frac{\left(s_{i}^{(t)}-\zeta_{j}\right)}{\left(s_{i}^{(t)}-s_{j}^{(t)}\right)}=\left(1+O\left(\epsilon^{\prime}\right)\right)^{n-1}=1+(n-1) O\left(\epsilon^{\prime}\right)=1+O\left(\epsilon^{\prime}\right)
$$




$$
\begin{aligned}
& U_{i}=1+O\left(\epsilon^{\prime}\right), \\
& 1-U_{i}=O\left(\epsilon^{\prime}\right), \\
& \epsilon_{i}^{\prime \prime}=O\left(\epsilon^{\prime}\right)^{2} .
\end{aligned}
$$

Since from (15), $\epsilon_{i}^{\prime}=O(\epsilon)^{3}$. Thus,

$$
\begin{aligned}
\epsilon_{i}^{\prime \prime} & =O\left((\epsilon)^{3}\right)^{2}, \\
\epsilon_{i}^{\prime \prime} & =O(\epsilon)^{6} .
\end{aligned}
$$

From the third step of NIM12, we have

$$
\begin{aligned}
& v_{i}^{(t)}-\zeta_{i}=u_{i}^{(t)}-\zeta_{i}-w_{i}\left(u_{i}^{(t)}\right), \\
& \epsilon_{i}^{\prime \prime \prime}=\epsilon_{i}^{\prime \prime}-\epsilon_{i}^{\prime \prime} \frac{w_{i}\left(u_{i}^{(t)}\right)}{\epsilon_{i}^{\prime \prime}}, \\
& \epsilon_{i}^{\prime \prime \prime}=\epsilon_{i}^{\prime \prime}\left(1-G_{i}\right),
\end{aligned}
$$

where

$$
\begin{aligned}
& G_{i}=\frac{w_{i}\left(u_{i}\right)}{\epsilon_{i}^{\prime \prime}}=\prod_{\substack{j \neq i \\
j=1}}^{n} \frac{\left(u_{i}^{(t)}-\zeta_{j}\right)}{\left(u_{i}^{(t)}-u_{j}^{(t)}\right)}, \\
& \frac{u_{i}^{(t)}-\zeta_{j}}{u_{i}^{(t)}-u_{j}^{(t)}}=1+\frac{u_{j}^{(t)}-\zeta_{j}}{u_{i}^{(t)}-u_{j}^{(t)}}=1+O\left(\epsilon_{i}^{\prime \prime}\right) .
\end{aligned}
$$

With the same argument used in (16), we have

$$
\prod_{\substack{j \neq i \\ j=1}}^{n} \frac{\left(u_{i}^{(t)}-\zeta_{j}\right)}{\left(u_{i}^{(t)}-u_{j}^{(t)}\right)}=\left(1+O\left(\epsilon^{\prime \prime}\right)\right)^{n-1}=1+(n-1) O\left(\epsilon^{\prime \prime}\right)=1+O\left(\epsilon^{\prime \prime}\right) .
$$

Therefore,

$$
\begin{aligned}
& G_{i}=1+O\left(\epsilon^{\prime \prime}\right), \\
& 1-G_{i}=O\left(\epsilon^{\prime \prime}\right), \\
& \epsilon_{i}^{\prime \prime \prime}=O\left(\epsilon^{\prime \prime}\right)^{2} .
\end{aligned}
$$

Since from (17) $\epsilon_{i}^{\prime \prime}=\mathrm{O}(\epsilon)^{6}$, we obtain

$$
\begin{aligned}
& \epsilon_{i}^{\prime \prime \prime}=O\left((\epsilon)^{6}\right)^{2}, \\
& \epsilon_{i}^{\prime \prime \prime}=O(\epsilon)^{12} .
\end{aligned}
$$

Hence, (21) proves 12th order convergence. 
Table 1 Number of operations (real arithmetic)

\begin{tabular}{llll}
\hline Methods & $\mathrm{AS}_{m}$ & $\mathrm{M}_{m}$ & $\mathrm{D}_{m}$ \\
\hline NIM12 & $7 m^{2}+O(m)$ & $5 m^{2}+O(m)$ & $2 m^{2}+O(m)$ \\
NIM10 & $22 m^{2}+O(m)$ & $18 m^{2}+O(m)$ & $2 m^{2}+O(m)$ \\
\hline
\end{tabular}

\section{Computational aspect}

In this section, we compare the computational efficiencies of methods NIM10 and NIM12. As presented in [11], we can formulate the efficiency indices as follows:

$$
\rho(\mathrm{NIM} 12, \mathrm{NIM} 10)=\left(\frac{E(\mathrm{NIM} 12)}{E(\mathrm{NIM} 10)}-1\right) \times 100
$$

or

$$
\rho(\mathrm{NIM} 10, \mathrm{NIM} 12))=\left(\frac{E(\mathrm{NIM} 10)}{E((\mathrm{NIM} 12))}-1\right) \times 100
$$

where

$$
E(I N)=\frac{\log \mathbf{r}}{\mathbf{Q}} .
$$

The cost of computation is represented by $\mathbf{Q}[11]$ and convergence order by $\mathbf{r}$ given as

$$
\mathbf{Q}=\mathbf{Q}(m)=w_{a s} A S_{m}+w_{m} M_{m}+w_{d} D_{m} .
$$

Using the expression of $\mathbf{Q}$ in (24), we have

$$
E L(m)=\left(\frac{\log \mathbf{r}}{w_{a s} A S_{m}+w_{m} M_{m}+w_{d} D_{m}}\right) .
$$

The number of operations of real arithmetic of a complex polynomial with real and complex roots reduces to operations of real arithmetic as given in Table 1.

Figure 1(a)-(b) shows the percentage ratios of NIM10 and NIM12. It is evident from Fig. 1(a)-(b) that NIM12 is much better than NIM10.

Figure 1(a)-(b) shows the computational efficiency of simultaneous method NIM12 and NIM10 with respect to each other. Figure 1(a)-(b) clearly shows the dominance efficiency of our newly constructed method NIM12 over NIM10.

\section{Numerical results}

For numerical calculations, we use the following stopping criteria to terminate the computer programme using Maple 18 with 125-digit floating point arithmetic:

$$
e_{i}^{(t)}=\left\|r_{i}^{(t+1)}-r_{i}^{(t)}\right\|_{2}<10^{-30}
$$

where $e_{i}^{(t)}$ represents the absolute error. In all the tables, CPU means computational time in seconds. In all numerical calculations, we take $\alpha=12 / 130$.

\section{Application in engineering}

In this section, we also discuss some applications from engineering. 


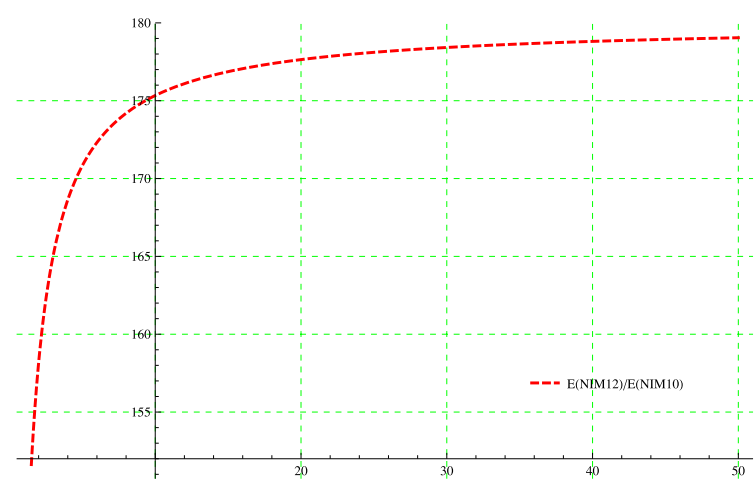

Fig 1(a)

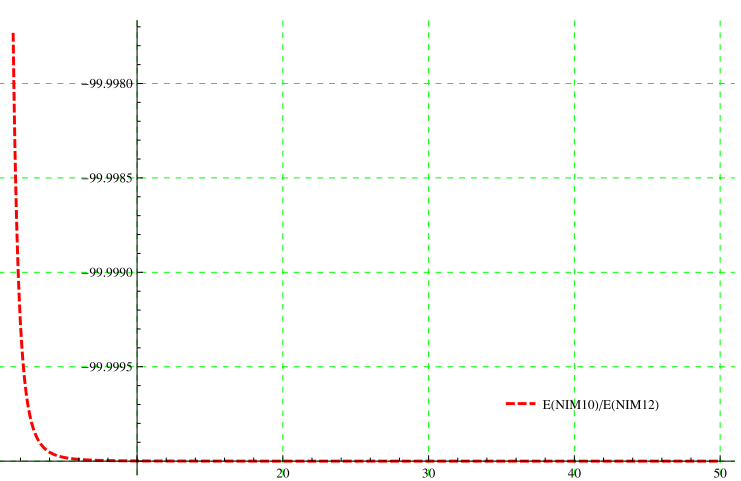

Fig 1(b)

Figure 1 Percentage computational efficiency of simultaneous method NIM12 w.r.t NIM10

Table 2 Residual errors of simultaneous methods NIM10 and NIM12 for finding all roots of $f_{1}(r)$

\begin{tabular}{llllllllll}
\hline Method & $\mathrm{CPU}$ & $\mathrm{e}_{1}^{(3)}$ & $\mathrm{e}_{2}^{(3)}$ & $\mathrm{e}_{3}^{(3)}$ & $\mathrm{e}_{4}^{(3)}$ & $\mathrm{e}_{5}^{(3)}$ & $\mathrm{e}_{6}^{(3)}$ & $\mathrm{e}_{7}^{(3)}$ & $\mathrm{e}_{8}^{(3)}$ \\
\hline NIM10 & 0.766 & $6.9 \mathrm{e}-10$ & $2.3 \mathrm{e}-12$ & $6.1 \mathrm{e}-11$ & $5.0 \mathrm{e}-11$ & $2.7 \mathrm{e}-9$ & $1.7 \mathrm{e}-11$ & $7.6 \mathrm{e}-9$ & $1.0 \mathrm{e}-13$ \\
NIM12 & 0.250 & $2.7 \mathrm{e}-25$ & $4.5 \mathrm{e}-25$ & $1.1 \mathrm{e}-23$ & $1.6 \mathrm{e}-23$ & $5.0 \mathrm{e}-24$ & $1.2 \mathrm{e}-23$ & $4.5 \mathrm{e}-24$ & $8.0 \mathrm{e}-25$ \\
\hline
\end{tabular}

Example 1 ([27]) Consider

$$
f_{1}(r)=(r+1)(r+2)\left(r^{2}-2 r+2\right)\left(r^{2}+1\right)(r-2)(r+2-i)
$$

with exact roots

$$
\zeta_{1}=-1, \quad \zeta_{2}=-2, \quad \zeta_{3,4}=1 \pm i, \quad \zeta_{5,6}= \pm i, \quad \zeta_{7}=2, \quad \zeta_{8}=-2+i .
$$

The initial guessed values have been taken as follows:

$$
\begin{aligned}
& \stackrel{(0)}{r_{1}}=-1.3+0.2 i, \quad \stackrel{(0)}{r_{2}}=-2.2-0.3 i, \quad \stackrel{(0)}{r}_{3}=1.3+1.2 i, \quad \stackrel{(0)}{r}_{4}=0.7-1.2 i, \\
& \stackrel{(0)}{r}_{5}=-0.2+0.8 i, \quad \stackrel{(0)}{r}_{6}=0.2-1.3 i, \quad \stackrel{(0)}{r}_{7}=2.2-0.3 i, \quad \stackrel{(0)}{r}_{8}=-2.2+0.7 i .
\end{aligned}
$$

Table 2 evidently illustrates the supremacy behavior of NIM12 over NIM10 in estimated absolute error and in CPU time on the same number of iterations $n=3$ for guesstimating all roots of the nonlinear polynomial equation used in Example 1. 
Table 3 Residual errors of simultaneous methods NIM10 and NIM12 for finding all roots of $f_{2}(r)$

\begin{tabular}{llllll}
\hline Method & CPU & $\mathrm{e}_{1}^{(4)}$ & $\mathrm{e}_{2}^{(4)}$ & $\mathrm{e}_{3}^{(4)}$ & $\mathrm{e}_{4}^{(4)}$ \\
\hline NIM10 & 0.071 & $1.3 \mathrm{e}-25$ & $1.4 \mathrm{e}-25$ & $4.5 \mathrm{e}-28$ & $1.2 \mathrm{e}-28$ \\
NIM12 & 0.031 & 0.0 & 0.0 & $1.3 \mathrm{e}-37$ & $1.3 \mathrm{e}-38$ \\
\hline
\end{tabular}

Example 2 ([28] Fractional conversion) The expression described in [29, 30]

$$
f_{2}(r)=r^{4}-7.79075 r^{3}+14.7445 r^{2}+2.511 r-1.674
$$

is the fractional conversion of nitrogen, hydrogen feed at $250 \mathrm{~atm}$. and 227k.

The exact roots of (27) are:

$$
\zeta_{1}=3.9485+0.3161 i, \quad \zeta_{2}=3.9485-0.3161 i, \quad \zeta_{3}=-0.3841, \quad \zeta_{4}=0.2778
$$

The initial calculated values of (27) have been taken as follows:

$$
\stackrel{(0)}{r_{1}}=3.5+0.3 i, \quad \stackrel{(0)}{r}_{2}=3.5-0.3 i, \quad \stackrel{(0)}{r}_{3}=-0.3+0.01 i, \quad \stackrel{(0)}{r}_{4}=1.8+0.01 i
$$

Table 3 evidently illustrates the supremacy behavior of NIM12 over NIM10 in estimated absolute error and in CPU time on the same number of iterations $n=4$ for guesstimating all roots of the nonlinear polynomial equation used in Example 2.

Example 3 ([27] Continuous stirred tank reactor (CSTR)) An isothermal CSTR is considered here. Items $E_{1}$ and $E_{2}$ are fed to the reactor at rates of $\mathrm{R}$ and $\mathrm{q}-\mathrm{R}$, respectively. Complex chain reactions are developed in the reactor given as follows:

$$
E_{1}+E_{2} \longrightarrow E_{3}, \quad E_{3}+E_{2} \longrightarrow E_{4}, \quad E_{4}+E_{2} \longrightarrow E_{5}, \quad E_{4}+E_{2} \longrightarrow E_{6}
$$

This problem was first tested by Douglas (see [31]), and the following equation of transfer function of the rector was found:

$$
H_{c} \frac{2.98(r+2.25)}{(r+1.45)(r+2.85)^{2}(r+4.35)}=-1,
$$

$H_{c}$ being the gain of the proportional controller. This transfer function yields the following nonlinear equation by taking $H_{c}=0$ :

$$
f_{3}(r)=r^{4}+11.50 r^{3}+47.49 r^{2}+83.06325 r+51.23266875=0 .
$$

The transfer function has four negative real roots, i.e., $r_{1}=-1.45, r_{2}=-2.85, r_{3}=-2.85$, $r_{4}=-4.45$.

The initial calculated values of (29) have been taken as follows:

$$
\stackrel{(0)}{r_{1}}=-1.0, \quad \stackrel{(0)}{r}_{2}=-1.1, \quad \stackrel{(0)}{r}_{3}=-2.2, \quad \stackrel{(0)}{r}_{4}=-3.9 .
$$

Table 4 evidently illustrates the supremacy behavior of NIM12 over NIM10 in estimated absolute error and in CPU time on the same number of iterations $n=4$ for guesstimating all roots of the nonlinear polynomial equation used in Example 3. 
Table 4 Residual errors of simultaneous methods NIM10 and NIM12 for finding all roots of $f_{3}(r)$

\begin{tabular}{llllll}
\hline Method & CPU & $\mathrm{e}_{1}^{(4)}$ & $\mathrm{e}_{2}^{(4)}$ & $\mathrm{e}_{3}^{(4)}$ & $\mathrm{e}_{4}^{(4)}$ \\
\hline NIM10 & 0.016 & 0.1 & 0.05 & 0.20 & $1.9 \mathrm{e}-3$ \\
NIM12 & 0.015 & $1.1 \mathrm{e}-8$ & $1.1 \mathrm{e}-8$ & $8.0 \mathrm{e}-32$ & $2.7 \mathrm{e}-32$ \\
\hline
\end{tabular}

\section{Conclusion}

We have developed here a family of three-step simultaneous methods of order 12 which is the highest order derivative-free simultaneous iterative method among existing methods in the literature. From Tables 1-4 and Fig. 1(a), (b), we observe that our family of derivative-free simultaneous methods NIM12 is admirable in terms of efficiency, CPU time, and residual errors as compared to the NIM10 method.

Funding

The authors declare that there is no funding available for this paper.

Availability of data and materials

Not applicable.

\section{Declarations}

\section{Competing interests}

The authors declare that they have no competing interests.

\section{Authors' contributions}

All authors read and approved the final manuscript.

\section{Author details}

${ }^{1}$ Department of Mathematics and Statistics, Riphah International University I-14, Islamabad 44000, Pakistan. ${ }^{2}$ Department of Mathematics, NUML, Islamabad, Pakistan. ${ }^{3}$ Department of Mathematics, Faculty of Arts and Sciences, Yildiz Technical University, Esenler, 34210 Istanbul, Turkey. ${ }^{4}$ Department of Mathematics, Anand International College of Engineering, Jaipur 303012, Rajasthan, India. ${ }^{5}$ Nonlinear Dynamics Research Center (NDRC), Ajman University, Ajman, UAE.

${ }^{6}$ Department of Mathematics, Research Institute of Natural Science, Hanyang University, Seoul, South Korea.

\section{Publisher's Note}

Springer Nature remains neutral with regard to jurisdictional claims in published maps and institutional affiliations.

Received: 30 August 2021 Accepted: 30 September 2021 Published online: 19 October 2021

\section{References}

1. Cordero, A., Huesoa, J.L., Martínez, E., Torregrosa, J.R.: A new technique to obtain derivative-free optimal iterative methods for solving nonlinear equations. J. Comput. Appl. Math. 252, 95-102 (2013)

2. Shah, F.A., Noor, M.A., Batool, M.: Derivative-free iterative methods for solving nonlinear equations. Appl. Math. Inf. Sci. 8(5), 2189-2193 (2014)

3. Agarwal, P., Filali, D., Akram, M., Dilshad, M.: Convergence analysis of a three-step iterative algorithm for generalized set-valued mixed-ordered variational inclusion problem. Symmetry 13(3), 444 (2021)

4. Sunarto, A., Agarwal, P., Sulaiman, J., Chew, J.V.L., Aruchunan, E.: Iterative method for solving one-dimensional fractional mathematical physics model via quarter-sweep and PAOR. Adv. Differ. Equ. 2021(1), 147 (2021)

5. Attary, M., Agarwal, P.: On developing an optimal Jarratt-like class for solving nonlinear equations. Ital. J. Pure Appl. Math. 43, 523-530 (2020)

6. Kumar, S., Kumar, D., Sharma, J.R., Cesarano, C., Agarwal, P., Chu, Y.M.: An optimal fourth order derivative-free numerical algorithm for multiple roots. Symmetry 12(6), 1038 (2020)

7. Naseem, A., Rehman, M.A., Abdeljawad, T.: Computational methods for non-linear equations with some real world applications and their graphical analysis. Intell. Autom. Soft Comput. 30(3) 805-819 (2021)

8. Proinov, P.D., Vasileva, M.T.: On a family of Weierstrass-type root-finding methods with accelerated convergence. Appl. Math. Comput. 273, 957-968 (2016)

9. Kanno, S., Kjurkchiev, N., Yamamoto, T.: On some methods for the simultaneous determination of polynomial zeros. Jpn. J. Appl. Math. 13, 267-288 (1995)

10. Proinov, P.D., Ivanov, S.I.: Convergence analysis of Sakurai-Torii-Sugiura iterative method for simultaneous approximation of polynomial zeros. J. Comput. Appl. Math. 357, 56-70 (2019)

11. Petkovic, M.S., Petkovic, L.D., Džunic, J.: On an efficient simultaneous method for finding polynomial zeros. Appl. Math. Lett. 28, 60-65 (2014)

12. Mir, N.A., Muneer, R., Jabeen, I.: Some families of two-step simultaneous methods for determining zeros of non-linear equations. ISRN Appl. Math. 2011, Article ID 817174 (2011) 
13. Nourein, A.W.M.: An improvement on two iteration methods for simultaneously determination of the zeros of a polynomial. Int. J. Comput. Math. 6, 241-252 (1977)

14. Aberth, O.: Iteration methods for finding all zeros of a polynomial simultaneously. Math. Comput. 27, 339-344 (1973)

15. Cosnard, M., Fraigniaud, P.: Finding the roots of a polynomial on an MIMD multicomputer. Parallel Comput. 15, 75-85 (1990)

16. Farmer, M.R.: Computing the zeros of polynomials using the divide and conquer approach. Ph.D. thesis, Department of Computer Science and Information Systems, Birkbeck, University of London (2014)

17. Cordero, A., Fardi, M., Ghasemi, M., Torregrosa, J.R.: Accelerated iterative methods for finding solutions of nonlinear equations and their dynamical behavior. Calcolo 51, 17-30 (2014)

18. Shams, M., Rafiq, N., Ahmad, B., Mir, N.A.: Inverse numerical iterative technique for finding all roots of non-linear equations with engineering applications. J. Math. 2021, Article ID 6643514 (2021)

19. Mir, N.A., Shams, M., Rafiq, N., Akram, S., Ahmed, R.: On family of simultaneous method for finding distinct as well as multiple roots of non-linear polynomial equation. Punjab Univ. J. Math. 52(6), 31-44 (2020)

20. Shams, M., Mir, N.A., Rafiq, N., Akram, S.: On dynamics of iterative techniques for non-linear equations with application in engineering. Math. Probl. Eng. 2020, Article ID 5853296 (2020)

21. Mir, N.A., Shams, M., Rafiq, N., Akram, S., Rizwan, M.: Derivative free iterative simultaneous method for finding distinct roots of polynomial equation. Alex. Eng. J. 59(3), 1629-1636 (2020)

22. Cholakov, S.I.: Local and semilocal convergence of Wang-Zheng's method for simultaneous finding polynomial zeros. Symmetry 2019, 736 (2019)

23. Proinov, P.D., Vasileva, M.T.: On the convergence of high-order Gargantini-Farmer-Loizou type iterative methods for simultaneous approximation of polynomial zeros. Appl. Math. Comput. 361, 202-214 (2019)

24. Weierstrass, K.: Neuer Beweis des Satzes, dass jede ganze rationale Function einer Veränderlichen dargestellt werden kann als ein Product aus linearen Functionen derselben Veränderlichen, Sitzungsber. Königl. Preuss. Akad. Wiss. Berlinn, vol. II, pp. 1085-1101 (1891)

25. Nedzhibov, G.H.: Iterative methods for simultaneous computing arbitrary number of multiple zeros of nonlinear equations. Int. J. Comput. Math. 90(5), 994-1007 (2013)

26. Turkyilmazoglu, M., A simple algorithm for high order Newton iteration formulae and some new variants. Hacet. J. Math. Stat. 49(1), 425-438 (2020)

27. Rafiq, N., Akram, S., Mir, N.A., Shams, M.: Study of dynamical behaviour and stability of iterative methods for non-linear equationswith application in engineering. Math. Probl. Eng. 2020, Article ID 3524324 (2020)

28. Chicharro, F.I., Cordero, A., Garrido, N., Torregrosa, J.R.: Stability and applicability of iterative methods with memory. J. Math. Chem. 57, 1282-1300 (2019)

29. Argyros, I.K., Magreñán, Á.A., Orcos, L.: Local convergence and a chemical application of derivative free root finding methods with one parameter based on interpolation. J. Math. Chem. 54, 1404-1416 (2016)

30. Shacham, M.: An improved memory method for the solution of a nonlinear equation. Chem. Eng. Sci. 44, 1495-1501 (1989)

31. Douglas, J.M.: Process Dynamics and Control, vol. 2. Prentice Hall, Englewood Cliffs (1972)

\section{Submit your manuscript to a SpringerOpen ${ }^{\circ}$ journal and benefit from:}

- Convenient online submission

- Rigorous peer review

- Open access: articles freely available online

- High visibility within the field

Retaining the copyright to your article

Submit your next manuscript at $>$ springeropen.com 